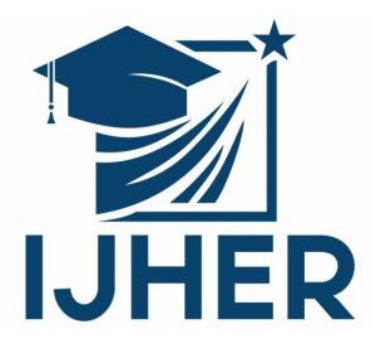

International Journal of Humanities and Educational Research

Volume 2, Issue 3, October 2020, p.1-12

İstanbul / Türkiye

\title{
TECHNICAL UNITY IN ANCIENT ARAB CRITICISM UNTIL THE END OF THE FOURTH CENTURY AH
}

\author{
http://dx.doi.org/10.47832/2757-5403.3-2.1
}

ISSN: 2757-5403

\begin{tabular}{|c|}
\hline \multicolumn{2}{c}{ Article Information } \\
\hline Article History: \\
\hline Received \\
$9 / 05 / 2020$ \\
Accepted \\
$20 / 07 / 2020$ \\
Available online \\
$01 / 10 / 2020$ \\
\hline \\
\hline
\end{tabular}

This article has been scanned by iThenticat No plagiarism detected

Copyright $@$ Published by Rimak Journal, www.rimakjournal.com

Rimar Academy, Fatih, Istanbul, 34093 Turkey All rights reserved

\begin{abstract}
AHMED SUFI 1
Abstract

The concept of artistic unity, in Ancient Arabic criticism, is achieved through the smallest unity. This is expressed through the poetic verse, which is meaningfully and rhythmically a unit that possess its own integrity. Thus, this makes it separate from the poem. However, this separation becomes a connection when it participates with other verses to build the poem. So, we may argue that this unity creates a separation on the level of the poetic line. On the other hand, it also forges connection on the level of the poem as a whole, and its causality with its neighboring verses. And through the numerous objects of the poem, the article "Unity" achieves by what was named Hosn AL kharoj to give a good connection to the point of assemblage of these objects.
\end{abstract}

Keywords: Unity of the Poetic Verse, Unity of the Arabic Poem.

${ }^{1} \mathrm{PhD}$ Student, University of Idlib, Syria.

\section{IJHER}

International Journal of Humanities and Educational Research

Volume 2, Issue 3, October 2020, p.1-12 


\section{وحدة القصيدة في النقد العربيّ القديم \\ حتى نهاية القرن الرابع الهجريّ}

2

ملخص

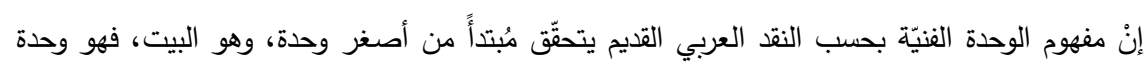

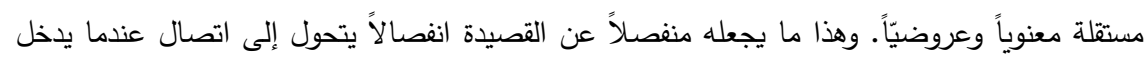

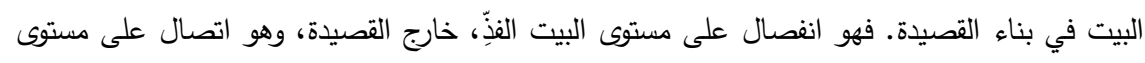

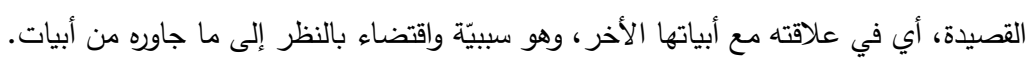

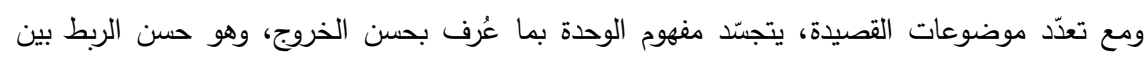

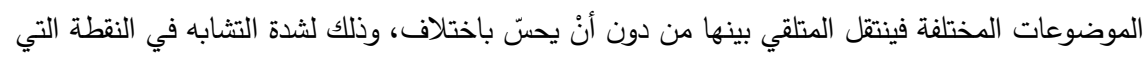
تربط كلا الموضوعين.

الكلمات المفتاحية: وحدة البيت الثعري، وحدة القصيدة العربية.

$$
\text { الوحدة الفنيّة في النقد العربي القديم: }
$$

المقدمـة

نعني بالوحدة الفنيّة، مجموعة الصفات الفنيّة التي تجعل من النصّ الشعريّ وحدةً فنية كاملةً. ومع أنّ مصطلح

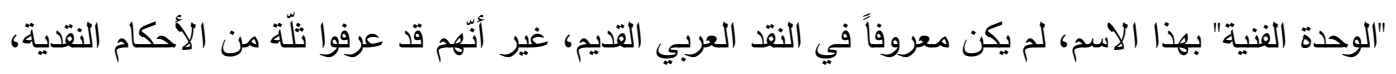

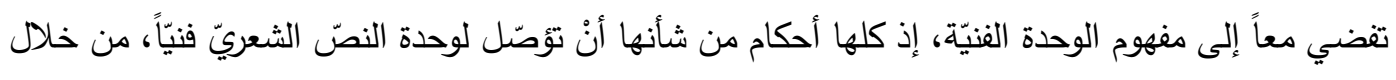
آليّة معينّة خاصّة بالنقد العربيّ القديم. سنقوم بدراستها على مستويات ثلاثة: الأوّل على مستوى الأجزاء

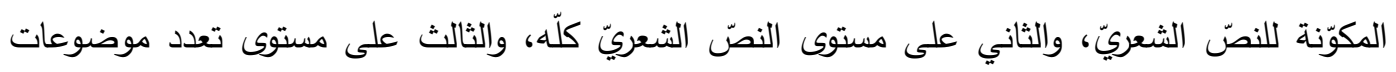

$$
\text { القصيدة. }
$$

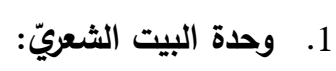

يتكوّن البيت الثعريّ في القصيدة العربية، وكما أقرّه النقّاد القدماء، من شطرين شعريين، وغالباً ما ينتهي

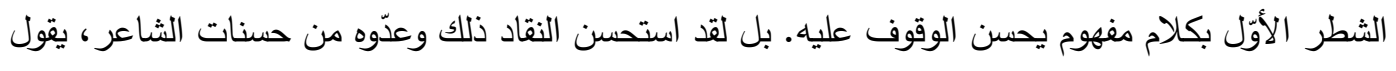

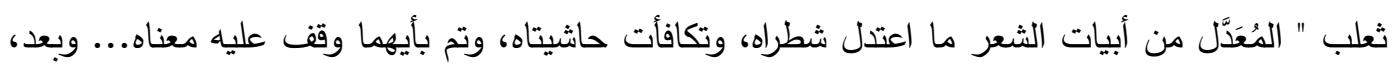

2 أحمد صوفي: طالب دراسات عليا (دكتور اه)، قسم اللغة العربيّة وآدابها، كليّة الآداب و العلوم الإنسانية، جامعة إدلب، سوريا.

\section{IJHER}

International Journal of Humanities and Educational Research

Volume 2, Issue 3, October 2020, p.1-12 
فهو أقرب الأشعار من البلاغة، وأحمدها عند أهل الرواية، وأثبهها بالأمثال السائرة؛ نحو: القتل أقل للقتل،

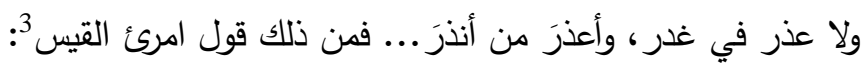

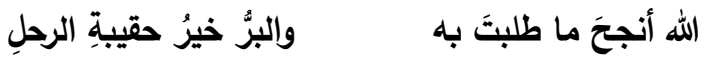

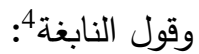

اليأسُ عما فاتَ يعقبُ راحةً وقال زهير بن أبي سُلمى 5.

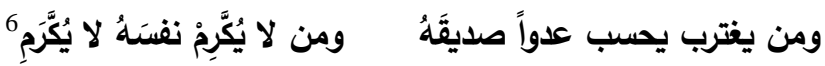

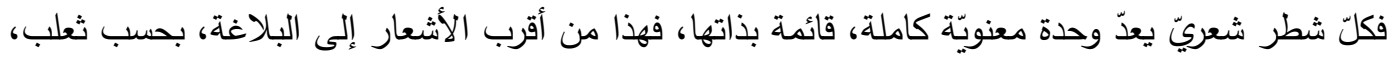

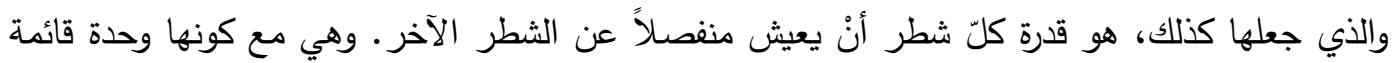

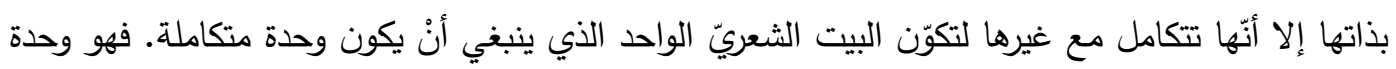
على المستوى العروضيّ تتكوّن من تفعيلات معروفة، وهو يجب أنْ يكون وحدة كذلك على المستوى المعنويّ.

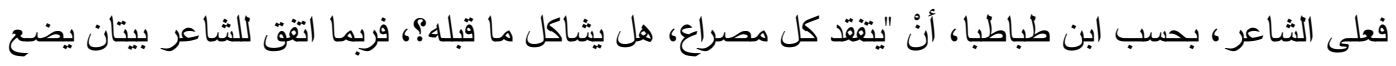

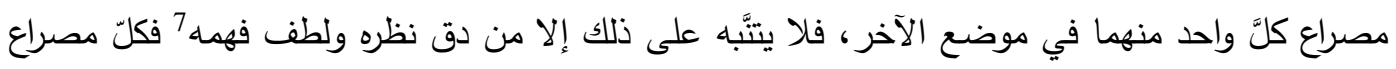

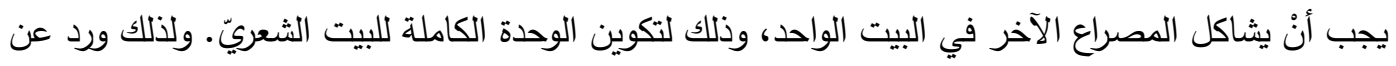

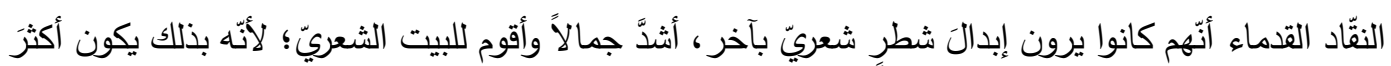
مشاكلةً، أي أكثرَ وحدةً. ومن ذلك ما ورد في عيار الثعر ، فابن طباطبا بعد أنْ يورد كلامه الذي أوردناه

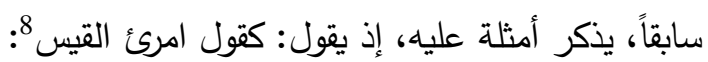

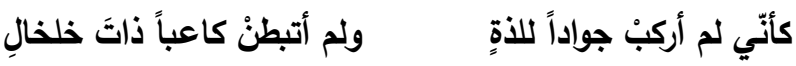

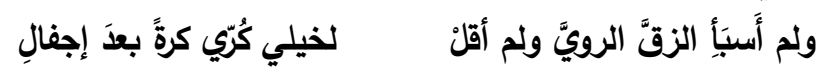

هكذا الرواية وهما بيتان حسنان، ولو وضع مصراع كل واحد منهما في موضع الآخر كان أشكل وأدخل في كري

$$
\text { كأني لم أركبْ جواداً ولم أقلْ لخيلي كرّي كرةً بعد إجفالٍ }
$$

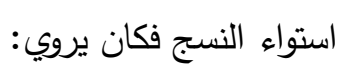

3 الكندي، امرؤ القيس بن حجر ، د.تا، ديوان امرئ القيس، تحقيق محمد أبو الفضل إبراهيم، د. ط، دار المعارف بمصر ، ص 238، وروايته

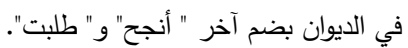

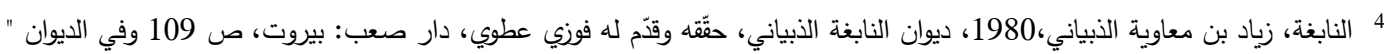

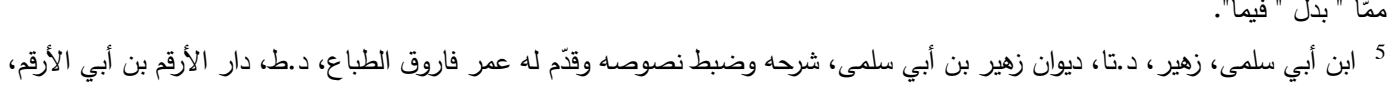

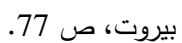

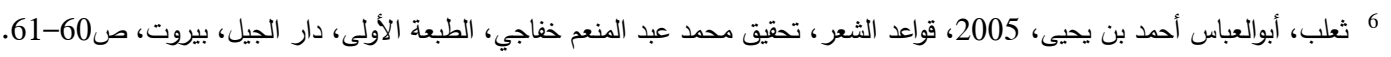

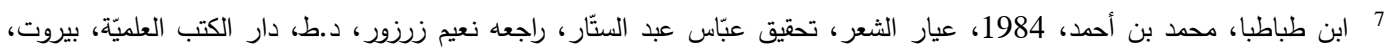
8 الكندي، ديوان امرئ القيس، ص 35.

\section{IJHER}

International Journal of Humanities and Educational Research

Volume 2, Issue 3, October 2020, p.1-12 


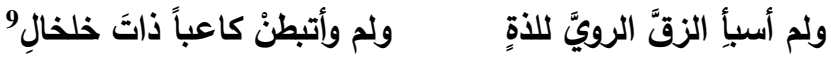

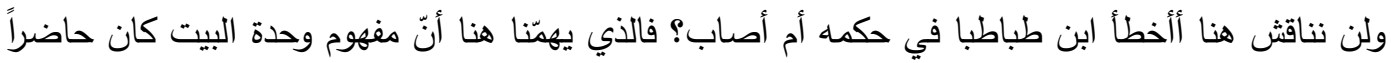

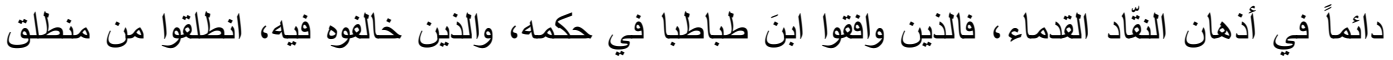

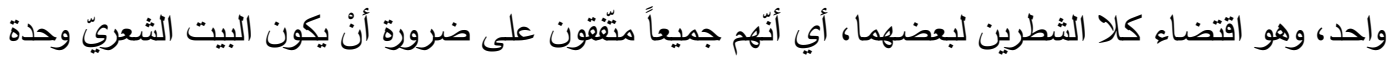

ولم يكتفوا بجعل البيت الثعري وحدة بتكامل شطريه معا. بل نظروا إلى البيت نفسه، فرأوا أنّه يجب أن يتساوى

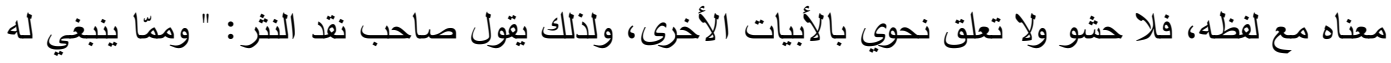

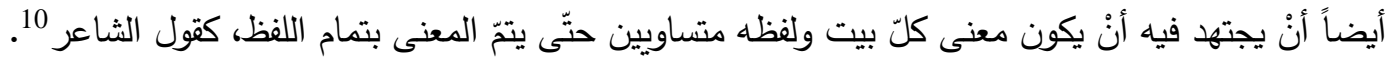

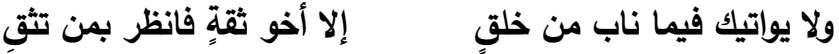

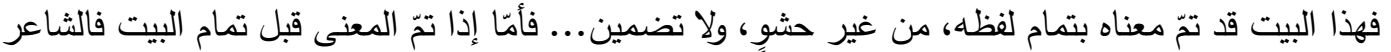

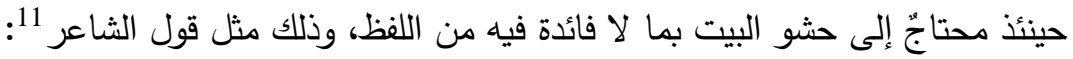

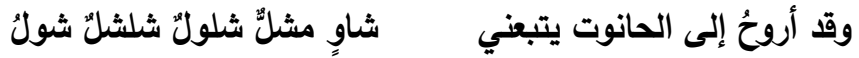

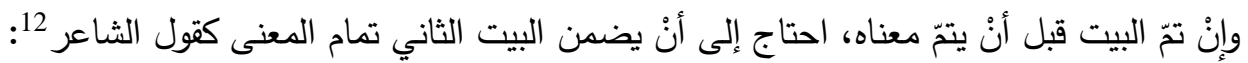

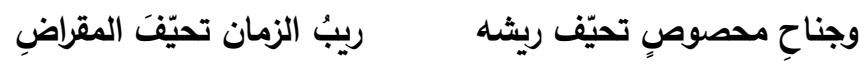

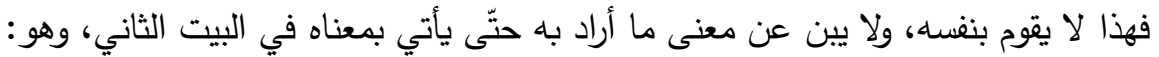

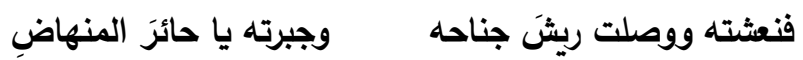

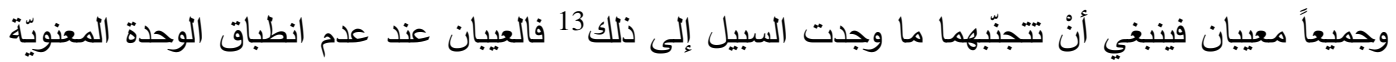

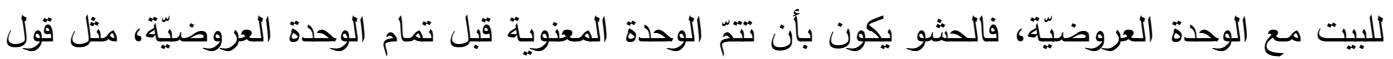

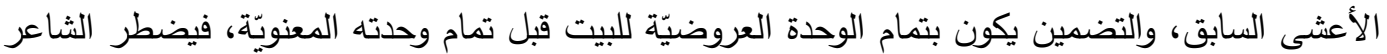
إلى إتمام المعنى في البيت اللاحق، وهذا العيب يسمى التضمين، وهو كما جاء بالمنصف: " شعر يحتاج

$$
9
$$
10 العرجي، عبد الله بن عمر، ديوان العرجيّ (رواية أبي الفتح عثمان بن جنّي)، 1956، شرحه وحقّقه خضر الطائي ورشيد العبيديّ، الطبعة

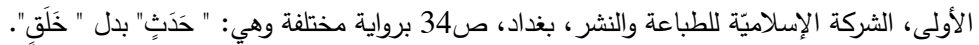

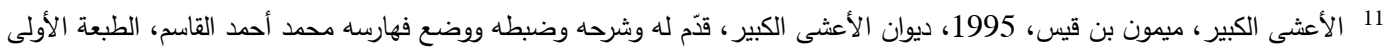

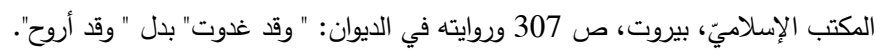

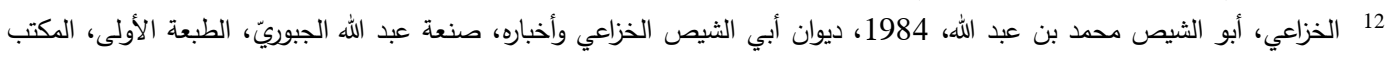
الإسلاميّ، بيروت، ص 78، 79. والرواية في الديوان: "وجناح مقصوص" بدل " محصوص"، ول، و" أنهضنَّه" بدل " ونعشته".

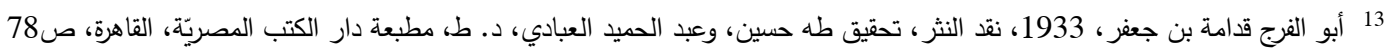

\section{IJHER}

International Journal of Humanities and Educational Research

Volume 2, Issue 3, October 2020, p.1-12 
أوّلّه إلى ما بعده... وذلك أنْ يبتدئ معنى في بيت لا يتمّ إلا بالبيت الثاني 14 وقد جاء في الصناعتين أنّ

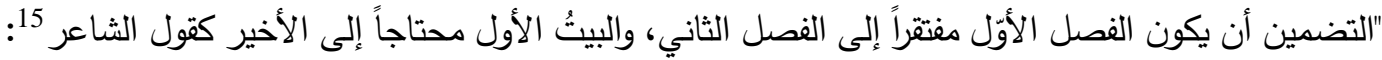

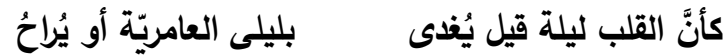

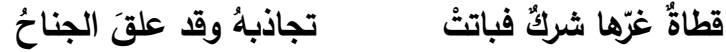

$$
\text { فلم يتمّ المعنى في البيت الأول حتى أتمّه في البيت الثاني، وهو قبيح } 16 .
$$
فكمال البيت الثعريّ لا يتحقق إلا بوجوده وحدة كاملة تستطيع أنْ تعيش منفصلة عن غيرها من الأبيات.

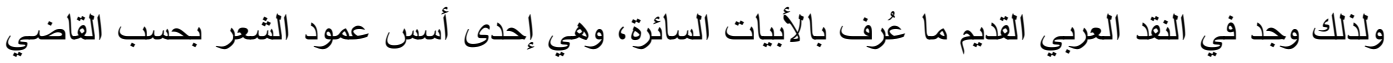
الجرجاني يقول: " وكانت العرب إنما تُفاضل بين الثعراء في الجودة والحسن بشرف المعنى وصحّته، وجزالة

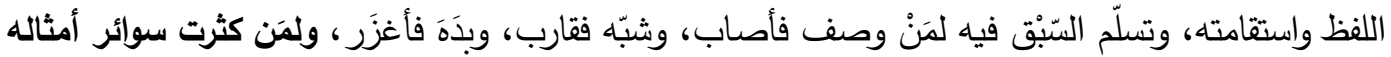
وشوارد أبياته...17 ولن تكثر سوائر الأمثال وشوارد الأبيات إلا إذا كان البيت وحدة وابته واملة على على المستويين

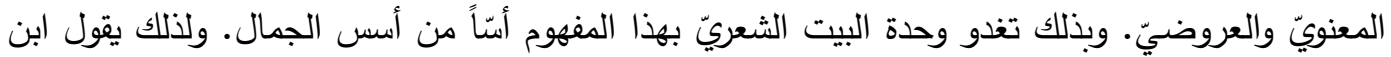
سلام واصفاً الفرزدق: " كان الفرزدق أكثرهم بيتاً مقلّداً 18 والبيت المقلّد كما يعرّفه ابن سلام: " البيت المستغني

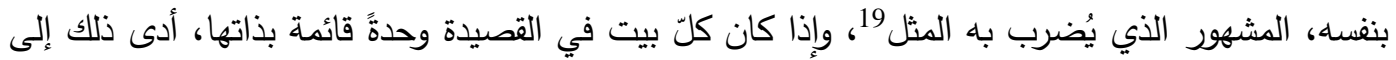
نوعٍ من التكرار على مستوى القصيدة. وبذلك يمكن أن نقول إنْ وحدة البيت الثعريّ تتحققّ بكونه مؤلفاً من

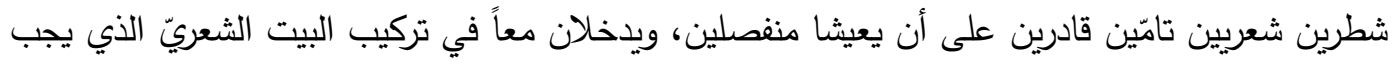
أنْ يكون وحدة تامّة أيضاً، والملاحظ كذلك أنّه ثمّة تشابه بين الثطرين الثعريين قد يصل إلى حد التماثل والمطابقة على المستوى العروضي، وإلى التشابه بالصفات والتشاكل على المستوى المعنوي، وهذا التشابه

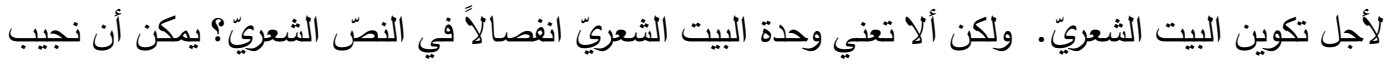

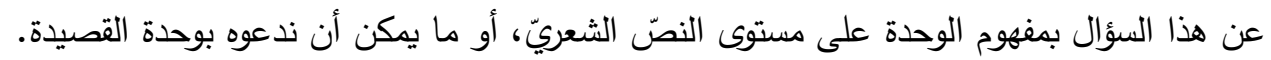

2.

لا يهمنا هنا التأصيل لمن قال أوّلاً بوحدة القصيدة، والذي يهمّنا هنا هو أن نعلم أنْ مفهوم وحدة القصيدة لم يكن غائباً عن النقّاد العرب القدماء، وإن كان هذا المعنى لله خصوصيته التي تميّزه من مفهوم الوحدة العضويّة

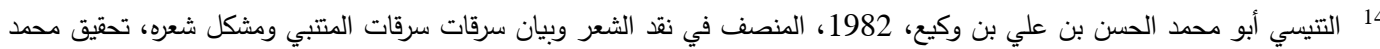

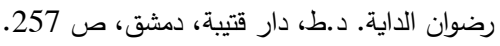
15 مجنون ليلى، قيس بن الملّّح، 2005، ديوان مجنون ليلى، قدّم لله وضبطه، وشرحه، وضئ، دوضع فهارسه صلاح الدين الهواري، الطبعة الأولى،

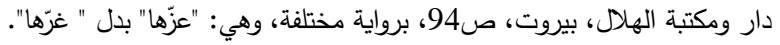
16 العسكريّ أبو هلال الحسن بن عبد الله، 1952، كتاب الصناعتين. تحقيق علي بن محمد البجاويّي، ومحمد أبو الفضل إبراهيم، الطبعة الطية

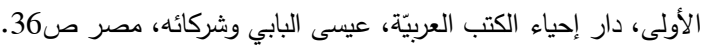

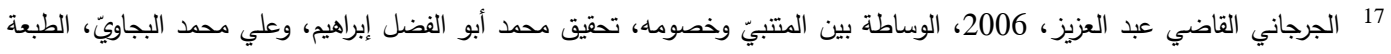
الأولى، المكتبة العصريّة، بيروت، صانس 39.

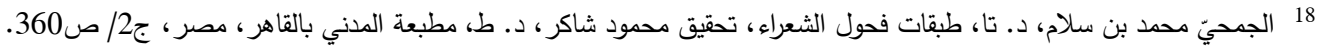

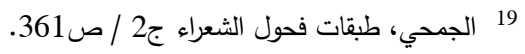

\section{IJHER}

International Journal of Humanities and Educational Research

Volume 2, Issue 3, October 2020, p.1-12 
التي ينادي بها النقّاد اليوم، فقد وجدنا أنّ النقّاد القدماء حرصوا على وحدة البيت الثعريّ الذي يعدّ اللبنة

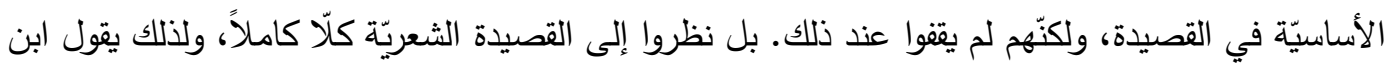
طباطبا " وينبغي للشاعر أنْ يتأمّل تأليف شعره، وتتسيق أبياته، ويقف على حسن تجاوزها أو قبحه؛ فيلائم

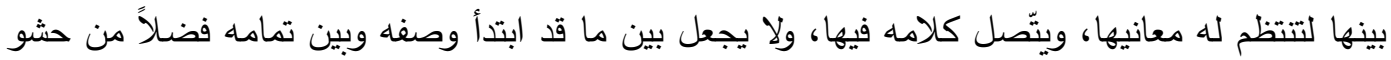
ليس من جنس ما هو فيه، فينسي السامع المعنى الذي يسوق القول إليه20 فمع أنّ كلّ بيت شعريّ هو وحدة ولئ قائمة بذاتها، إلا أنّ هذه الوحدة ينبغي لها أنْ تدخل في بناء القصيدة، ولذلك يجب أنس أن تكون هذه الوحدة وحدة

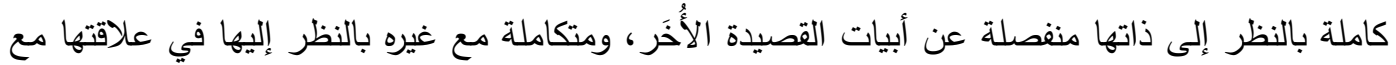

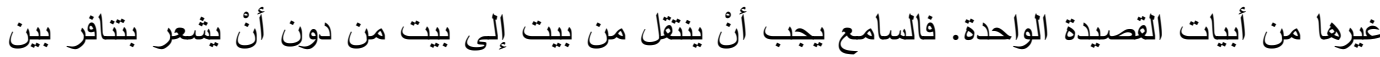

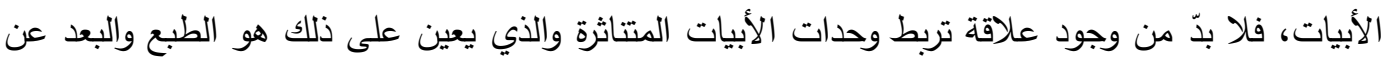
التكلّف. وإذا خرجت القصيدة إلى غير هذه الصفة، فإنّها لن تكون جميلة، بل ستكون بذلك دالة على التكلّف

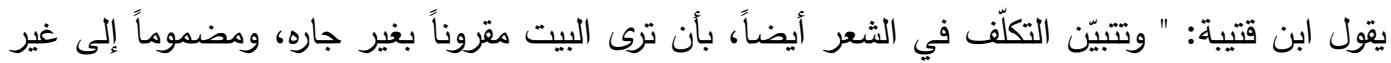

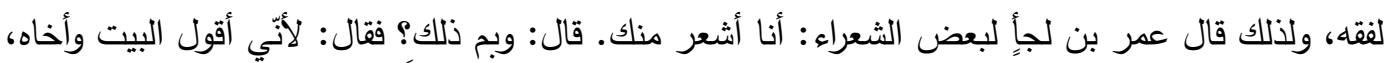
ولأنكّ تقول البيت وابن عمّه ${ }^{21}$ فوحدة القصيدة تقتضي أنْ يكون هناك تتاسب ما بين أبيات القصيدة، وهو

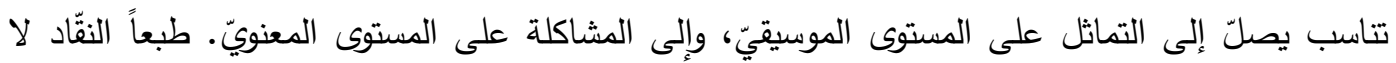
يتحدّثون هنا عن الوحدة على المستوى الموسيقيّ، وإنّما يقصدون الوحدة على المستوى المعنوي، واللفظيّ،

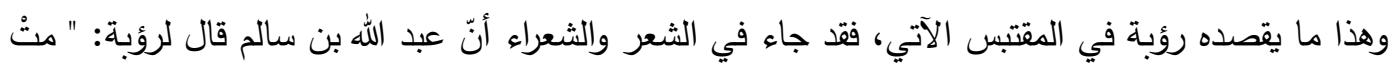

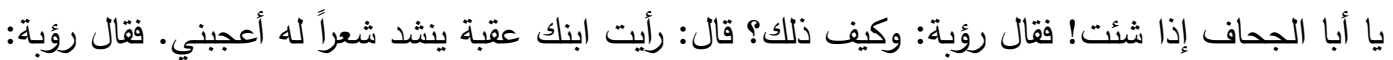

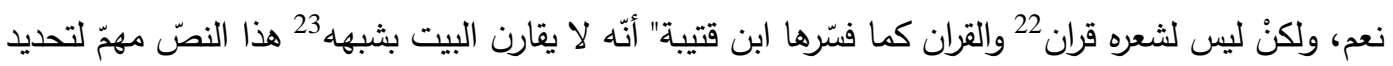

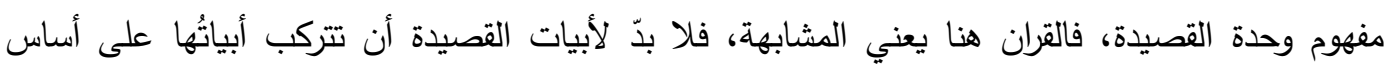

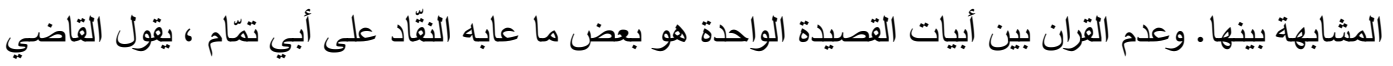

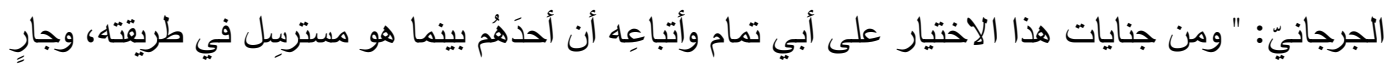

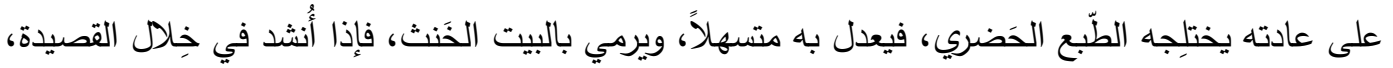

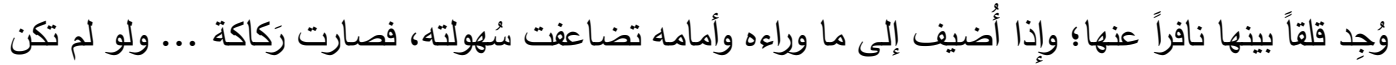
هذه الأبيات متتاسقة مقترنة، ولم يكن يجمعها قصيدة، وتسمع في حال واحدة لكان أخفى لعَيبِها، وأسترَ

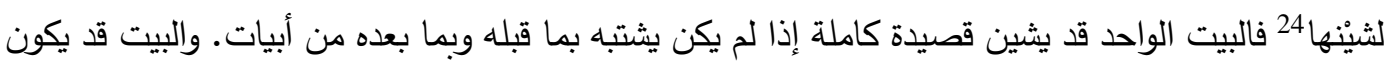

$$
20
$$
21 ابن قتيبة أبو محمد عبد الله، 1997، الثعر والثعراء، تحقيق عمر الطبّاع، الطبعة الثانية، شركة دار الأرقم بن أبي الأرقم، بيروت، ص صد

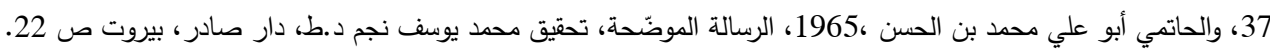


جميلاً بالنظر إليه خارج القصيدة، ولكنّه داخلها ليس كذلك. وهذا يعني كما ذكرنا سابقاً أنْ ثمّة مستويان يجب أنْ يلتزم بهما الثاعر في صوغه البيت الثعريّ، وهما التتاسق والوحدة على مستوى البيت الثعريّ الواحدة

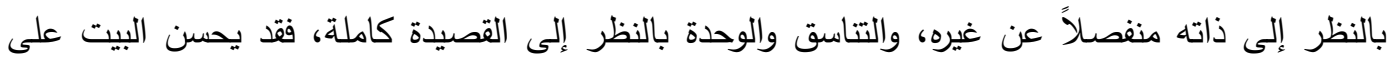
المستوى الأوّل، ولكنّه يكون قبيحاً على المستوى الثاني، وهذا ما قصده القاضي الجرجاني بقوله السابق. وقد أورد القاضي الجرجانيّ أمثلة على ذلك من شعر أبي تمام، نثبت بعضها بتمامها لنحسّ بالمقصود من من

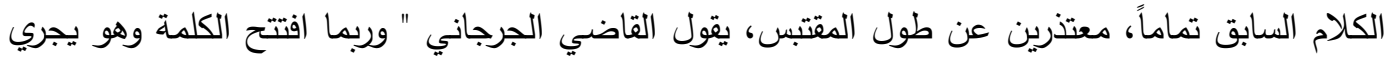

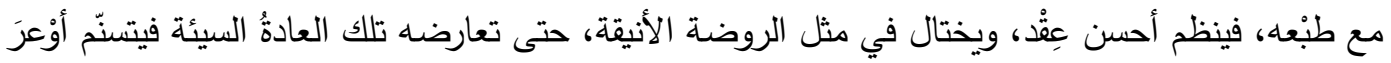
طريق، ويتعسّف أخشن مرْب، فيطمس تلك المحاسن، ويمحو طُلاوة ما قد قدّم؛ كما فعل أبو تمام في كثير من شعره؛ ومنه قوله

$$
\begin{aligned}
& \text { لو حار مرتادُ المنية لم يجدالا الفرلقَ على النفوس دليلا } \\
& \text { قالوا الرحيل؛ فما شككت بأنها نفسي من الانيا تريدُ رَحيلا } \\
& \text { الصبر أجملُ غير أنّ تلذذاً في الحب أحرى أن يكون جَميلا }
\end{aligned}
$$

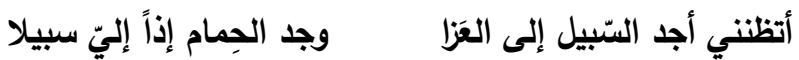

$$
\begin{aligned}
& \text { ردّ الجَموحِ الصّعبِ أسهلُ مُطلبا من ردّ دمْعِ قد أصسابَ مَسيلا }
\end{aligned}
$$

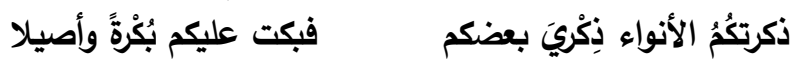

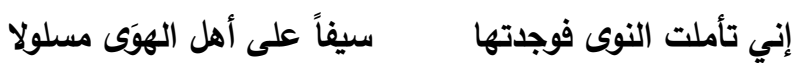$$
\text { ثم عدل عن النسيب فقال: ما: }
$$

لو جاز سلطان القُنوع وحُكْمُهُ في الخلق ما كان القليلُ قليلا

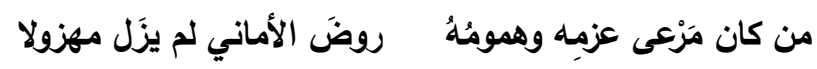

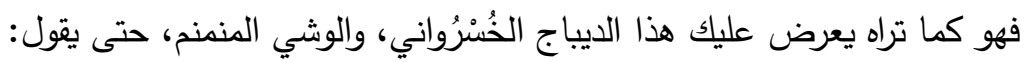

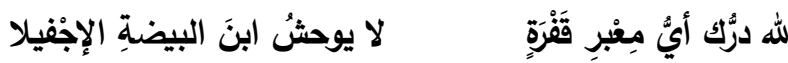

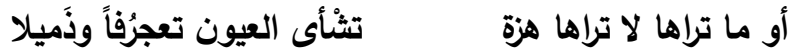

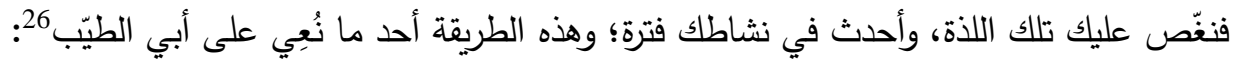

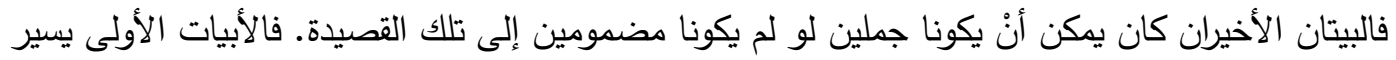

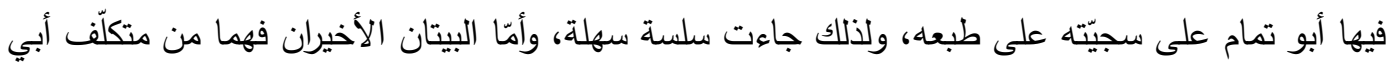
تمام من النمط البدوي. ولا يجوز أنْ يكون في قصيدة واحدة نمطان من الثعر : بدويّ وحضريّ، فالبدوي يجمل

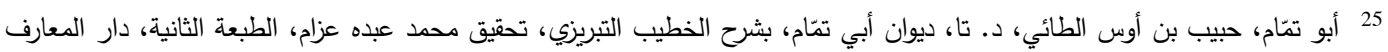

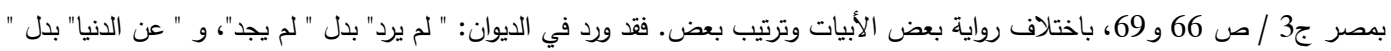
من الدنيا" في البيت الثاني، و " تلدداً" بدل " تلذذاً" في الثالث، و" سيفاً عليّ مع الهوى مسلولا" بدل " سيفاً على أهل الهوى مسلولا" في البيت بليت

$$
26 \text { الجرجاني، 2006، ص ص } 29 .
$$

\section{IJHER}

International Journal of Humanities and Educational Research

Volume 2, Issue 3, October 2020, p.1-12 
مع مثيله الثعر البدويّ، والحضريّ يجمل كذلك مع مثيله الثعر الحضريّ، وهذا الخلط بين الثعر البدويّ والثعر الحضريّ هو الذي أزرى ببعض شعر أبي تمام. ويذهب ابن طباطبا بوحدة القصيدة إلى أبعد من

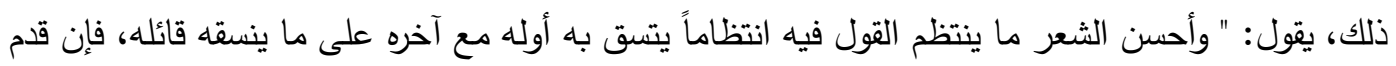
بيت على بيت دخله الخلل... بل يجب أن تكون القصيدة كلها ككلمة واحدة في اشتباه أولها بآخرها، نسجاً

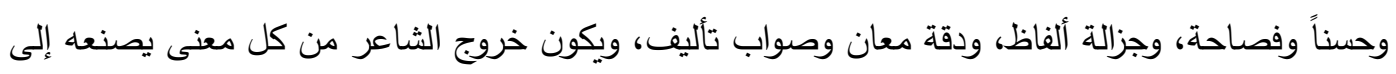

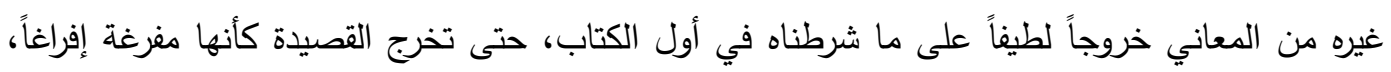

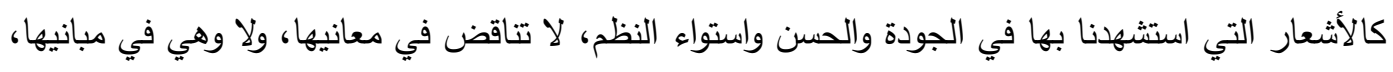

ولا تكلف في نسجها، تقتضي كل كلمة ما بعدها، ويكون ما بعدها متعلقاً بها مفتقراً إليها 27:

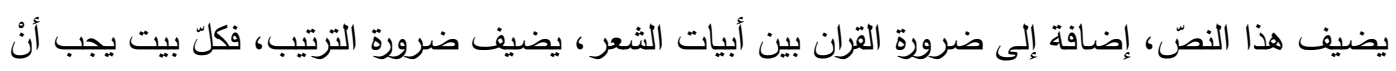

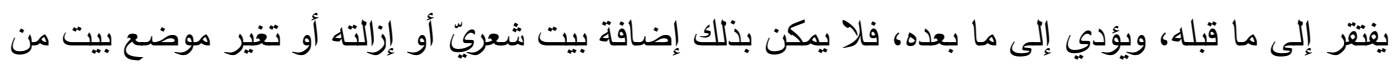

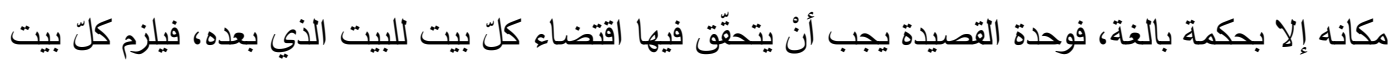

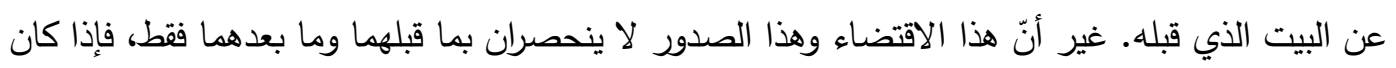

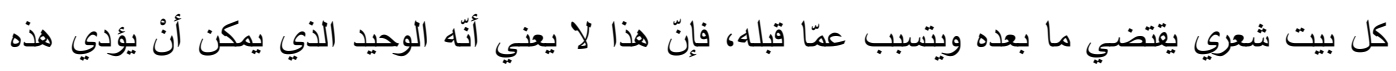

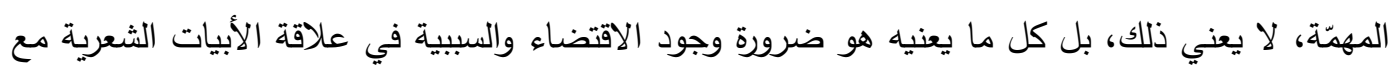

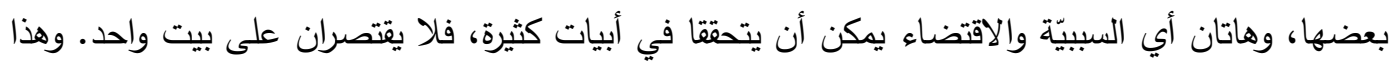

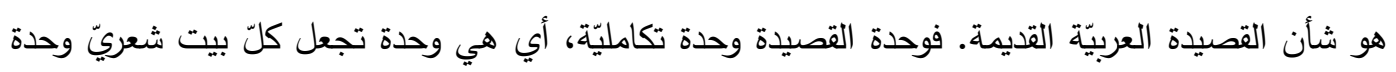
بذاته، وداخلاً في وحدة أعمّ منه وأكبر، هي وحدة القصيدة التي تتكوّن من مجموع وحدات البيوت الثعريّة التي من شرطها أنْ تكون متثابه في القصيدة الواحدة لتحقيق السببية والاقتضاء، وهو تثابه أو ربما تماثل

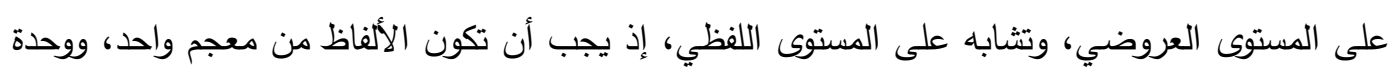

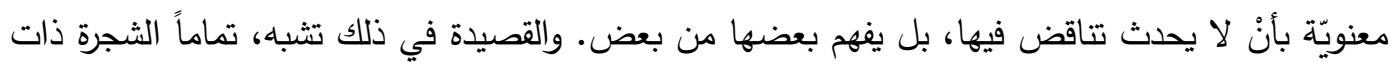

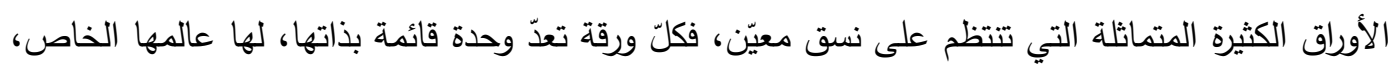
ولكنّها لا تتفل عن الثجرة (القصيدة) بل لها أثر في إعطاء معنى لهذه الثجرة ولتصتئمر في الحياة. فلو قطفنا بعض هذه الأوراق، فإنّ الثجرة ستبقى شجرة، ولو زيد فيها بعض الأوراق فانّها ستبقى شجرة أيضاً،

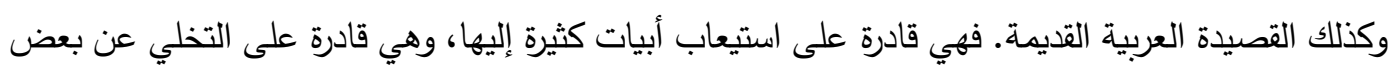

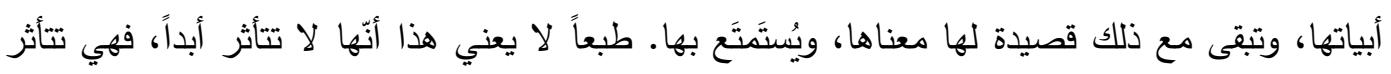

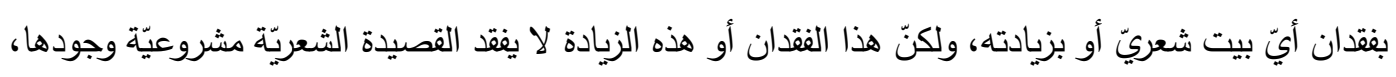

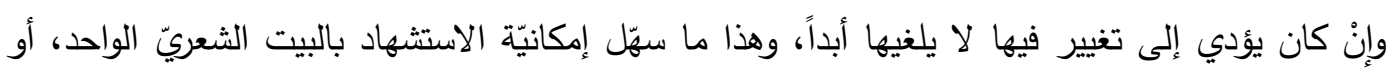
بالمقطّعة الثعريّة، أو بأبيات منتقاة من قصيدة واحدة، فهذا البيت، وهذه المقطّقة، وهذه الأبيات تبدو جميلة لسامعها، ومؤثّة فيه، وهي كذلك عندما تُتَلقّى في القصيدة كاملة غير مجتزئئةً

27 ابن طباطبا، 1984، ص 213.

\section{IJHER}

International Journal of Humanities and Educational Research

Volume 2, Issue 3, October 2020, p.1-12 
وتكمن الجماليّة في هذه الوحدة في قدرة البيت الثعريّ على أن يحيا وحيداً، وفي أنْ يدخل في تثكيل القصيدة الشعريّة، هذا من جهة النظر إلى البيت الثعريّ، ومن جهة النظر إلى القصيدة الشعريّة، تكمن الجماليّة في

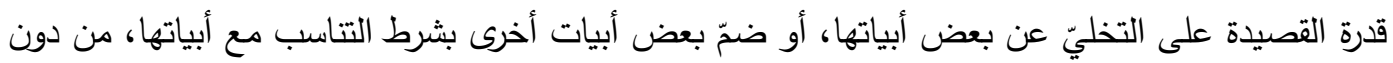
أن تقفد صفة القصيدة الثعريّة.

3. ت تعدّد موضوعات القصيدة:

حفاظاً على تحقيق الوحدة الفنية مع تعدد موضوعات القصيدة العربية القديمة، فإنّ النقّاد القدماء قد تحدّثوا عن عوامل الربط بين موضوع وموضوع وهو ما يُعرف عندهم بحسن التخلص، أو بحسن الخروج، فقد جاء في قواعد الثعر : "وقال أبو العباس في حسن الخروج عن بكاء الطلل، ووصف الإبل، وتحمّل الأظعان، وفراق الجيران، بغير : دع ذا، وعَدِّ عن ذا، واذكر ذا، بل من صدرِ إلى عجزٍ ، لا يتعداه إلى سواه، ولا يقرنه

$$
\text { قال الأعشى } 28 \text { يمدح الأسود بن الهنذر : }
$$

فالثطر الثاني من هذا البيت يخرج فيه الثاعر عن موضوع النسيب إلى مدح المدوح، ومع أنّ شطره الأوّل خطاب للمرأة، وشطره الثاني ابتداء في المدح، فإنّ البيت يُرى وحدة متتاسقة متثاكلة، وهذا الحركة من الثاعر هي التي تساعده على جعل القصيدة كلاً واحداً لا تتافر فيها مع وجود موضوعات مختلفة فيها، لأنّها تتقل

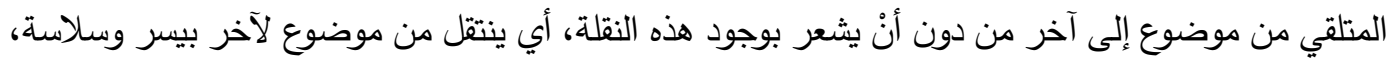

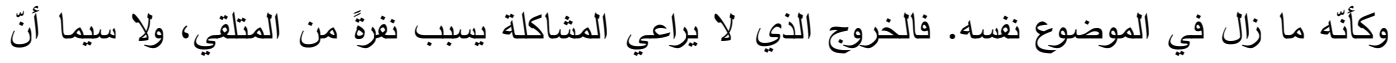

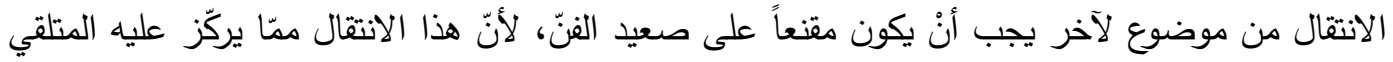

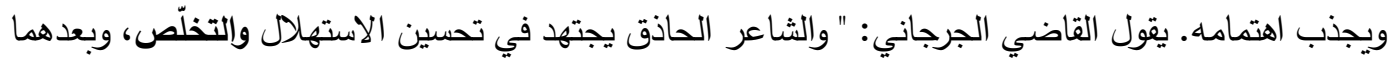
الخاتمة، فإنها المواقف التي تستعطف أسماع الحضور، وتستميلهم إلى الإصغاء 30 وحسن التخلص ليس

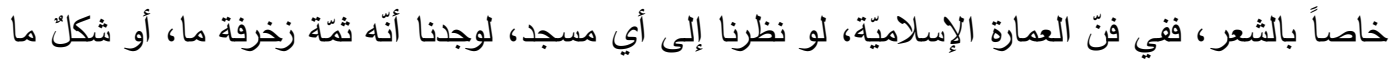

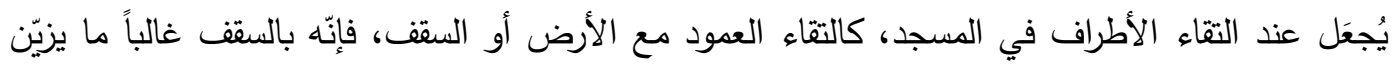

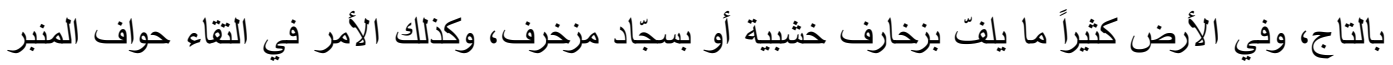

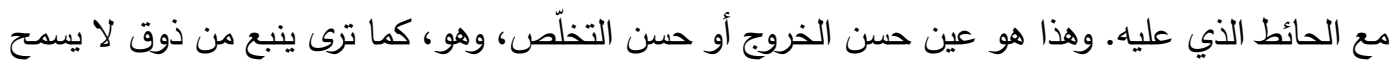

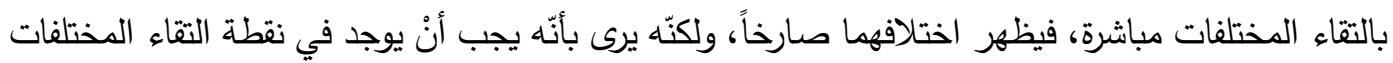

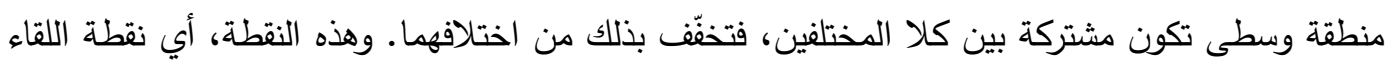

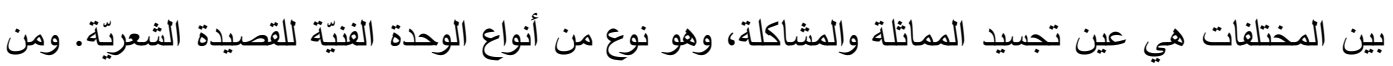

$$
\begin{aligned}
& 28 \text { الأعشى الكبير ، 1995، ص } 289 . \\
& 29 \text { ثُعب، 2005، ص486. } \\
& 30 \text { الجرجاني، 2006، ص ص } 51 .
\end{aligned}
$$

\section{IJHER}

International Journal of Humanities and Educational Research

Volume 2, Issue 3, October 2020, p.1-12 
حسن الخروج الذي يظهر ذلك واضحاً أبيات ذكرها ثعلب في قواعد الثعر لحسان بن ثابت رضي الله عنه، يقول: "وقال حسان 31، وقد تقدم في باب الهجاء، وأعدناه هاهنا؛ لأنه خروج على هذا السبيل من نسيب إلى دئ دابل هجاء:

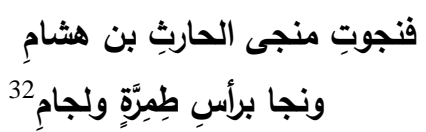

إن كنتِ كاذبةً الذي حدثنِي ترك الأحبةً أن يُقاتلَ دونهر

فالاختلاف بين النسيب والهجاء كبير جداً، لأنّ النسيب يحتاج إلى عذوبة في الأسلوب، ورقّة في المشاعر، في حين أنّ الهجاء يحتاج إلى قوة في الأسلوب وصخب في المشاعر، ومع هذا الاختلاف الكبير بينها استطاع حسان أنْ يحسن الخروج من النسيب إلى الهجاء من دون أنْ يُشعِرَ المتلقي بهذا الاختلاف بينهما، وهذه هي وظيفة حسن الخروج أو حسن التخلّص. وثمّة أمور أخرى كثيرة توّحد بين موضوعات القصيدة المتعدّدة، منها الوزن الموسيقيّ الواحد الذي يطبع القصيدة كلها بطابع واحد، ومنها القافيّة الواحدة التي تتركى رَنَّة صوتيّة واحدة في نهاية كل بيت في جميع موضوعات القصيدة، وهذا ما يجعل موضوعات القصيدة تبدو لتون

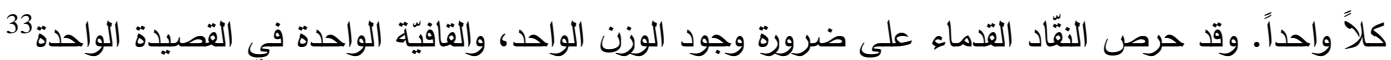
حفاظاً منهم على وحدة القصيدة الثعريّة. وأخيراً يمكن أنْ نقول إنْ مفهوم الوحدة الفنيّة في القصيدة العربيّة بحسب النقد العربي القديم يتحقّق مُبتتِداً من أصغر وحدةٍ حيّة في القصيدة العربية، وهو البيت الثعريّ الذي يمكن أنْ يُحفَظ وحيداً ويُستشهَّد به وحيداً،

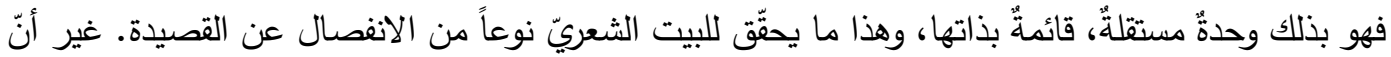

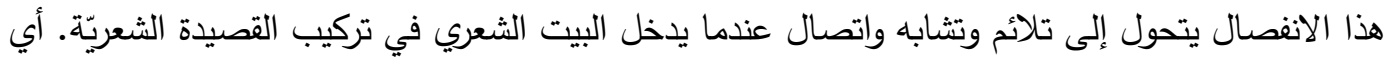

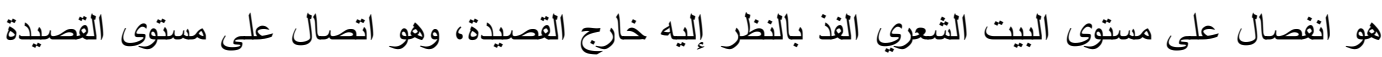

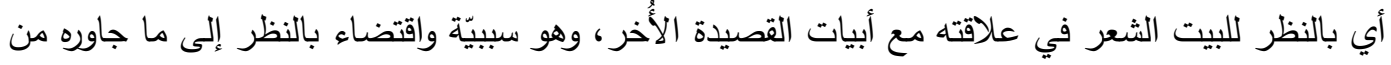
أبيات. ولا يقف مفهوم الوحدة الفنيّة عند هذا الحذّ، بل يتعدّاه ليحقّق الوحدة مع تعدّد موضوعات ليّة القيات القصيدة

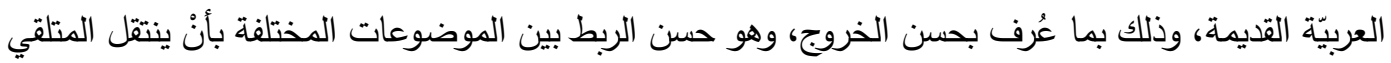

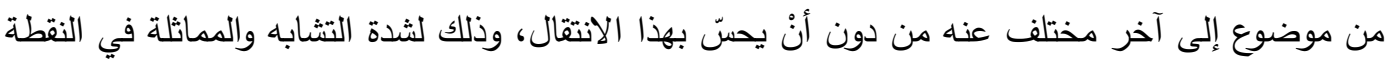
التي تربط كلا الموضوعين. وإذا كان حسن الخروج أو ما يعرف أيضاً بحسن التخلّص قادراً على إحداث الوحدة بين موضوعات القصيدة المختلفة، فإنّ وحدة الوزن ووحدة القافية تساعد، كذلك على إحداث هذه هـ الوحدة.

31 ابن ثابت، حسان، 1992، ديون حسان بن ثابت، شرح يوسف عيد، الطبعة الأولى، دار الجيل، بيروت، ص 346.

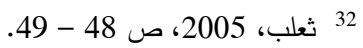

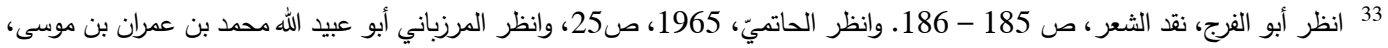

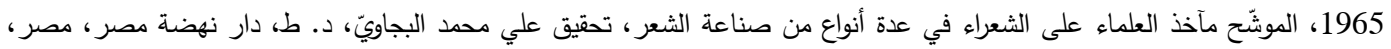
ص121، و122، وغيرها كثير من كتب النقد العربي القديم.

\section{IJHER}

International Journal of Humanities and Educational Research

Volume 2, Issue 3, October 2020, p.1-12 
المصادر والـــــراجــع:

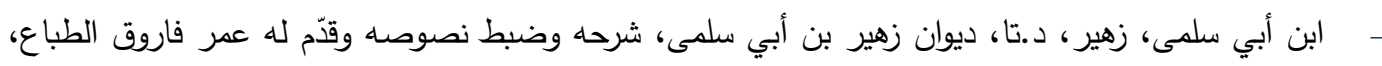
د.ط، دار الأرقم بن أبي الأرقم، بيروت.

ابن ثابت، حسان، 1992، ديون حسان بن ثابت، شرح يوسف الإن عيد، الطبعة الأولى، دار الجيل، بيروت.

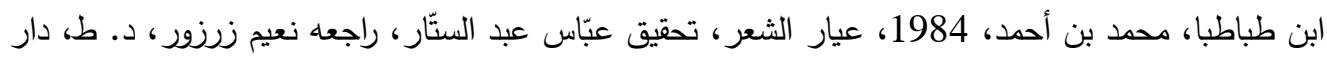

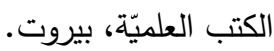

ابن قتيبة، أبو محمد عبد الله، 1997، الثعر والثعراء، تحقيق عمر الطبّاع، الطبعة الثانية، شركة دار الأرقم بن أبي الأرقم، بيروت.

أبو الفرج، قدامة بن جعفر، 1933، نقد النثر، تحقيق طه حسين، وعبد الحميد العبادي، د. ط، مطبعة دار الكتب

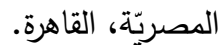
أبو الفرج، قدامة بن جعفر ، 1978، نقد الثعر ـ تحقيق كمال مصطفى، الطبعة الثالثة، مكتبة الخانجي، القاهرة.

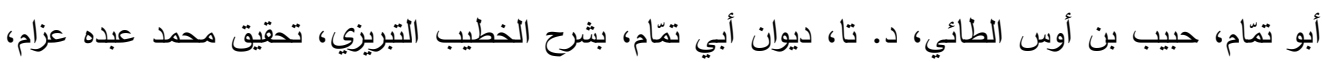

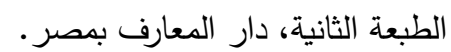
الأعشى الكبير، ميمون بن قيس، 1995، ديوان الأعشى الكبير، قدم له وشرحه وضبطه ووضع فهارسه محمد

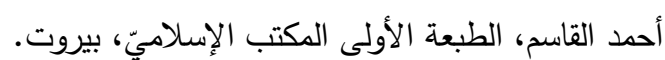
التتيسي، أبو محمد الحسن بن علي بن وكيع، 1982، المنصف في نقد الثنعر وبئيان سرقات سرقات المتنبي

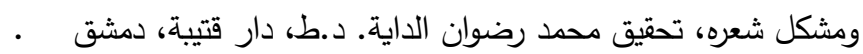
ثعلب، أبو العباس أحمد بن يحيى، 2005- قواعد الثعر . تحقيق محمد عبد المنعم خفاجي. الطبعة الأولى، دار

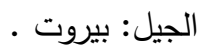
الجرجاني، القاضي عبد العزيز، 2006، الوساطة بين المتتبيّ وخصومه، تحقيق محمد أبو الفضل إبراهيم، وعلي

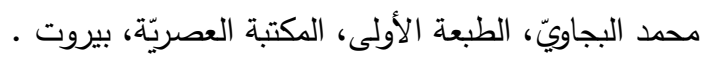

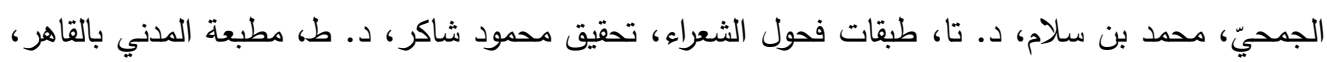
مصر. الحاتمي، أبو علي محمد بن الحسن 1965، الرسالة الموضّحة، تحقيق محمد يوسف نجم د.ط، دار صادر، بيروت. الخزاعي، أبو الشيص محمد بن عبد الله، 1984، ديوان أبي الثيص الخزاعي وأخباره، صنعة عبد الله الجبوريّ، الطبعة الأولى، الدكتب الإنلاميّ، بيروت.

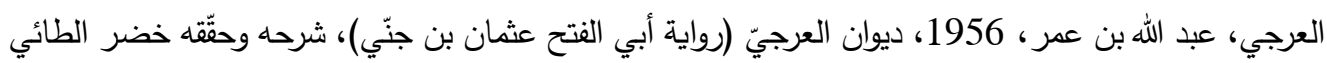

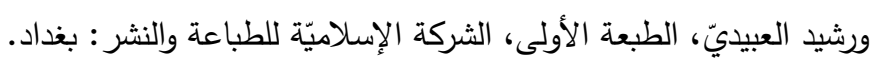

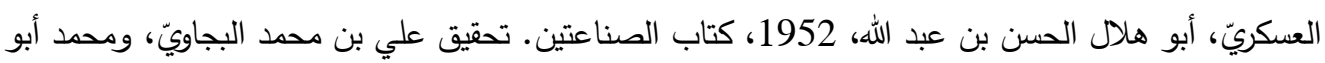
الفضل إبراهيم، الطبعة الأولى، دار إحياء الكتب العربيّة، عيسى البابي وشركائه، مصر . الكندي، امرؤ القيس بن حجر، د.تا، ديوان امرئ القيس، تحقيق محمد أبو الفضل إبراهيم، د. ط دار المعارف الفراه بمصر

\section{IJHER}

International Journal of Humanities and Educational Research Volume 2, Issue 3, October 2020, p.1-12 
مجنون ليلى، قيس بن الملوّ، 2005، ديوان مجنون ليلى، قدّم له وضبطه، وشرحه، ووضع فهارسه صلاح الدين

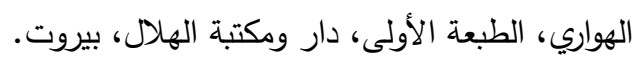
المرزباني، أبو عبيد الله محمد بن عمران بن موسى، 1965، الموشّّح مآخذ العلماء على الثعراء في عدة أنواع

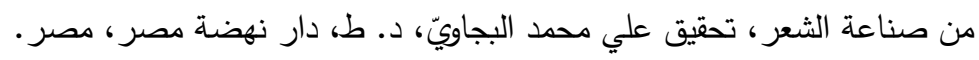

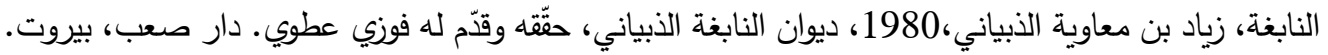

